\title{
ADDITION OF RITUXIMAB SIGNIFICANTLY IMPROVES OUTCOMES IN PATIENTS WITH DIFFUSE LARGE B-CELL LYMPHOMA - A SINGLE-CENTER, RETROSPECTIVE STUDY
}

\author{
David Belada1, Lukáš Smolej ${ }^{1}$, Monika Hrudková1, Pavla Štěpánková1, Alice Sýkorová1, Pavel Žák1, Jiří Bukač², \\ Jaroslav Malý 1
}

Charles University in Prague, Faculty of Medicine and University Hospital in Hradec Králové, Czech Republic: 2nd Department of Medicine, Division of Clinical Hematology ${ }^{1}$, Department of Medical Biophysics ${ }^{2}$

\begin{abstract}
Summary: CHOP chemotherapy has been used as a standard first-line treatment for diffuse large B-cell lymphoma since the 1970s. Phase III trials have shown that the addition of rituximab (R) to CHOP chemotherapy leads to significant improvements in response rate, progression-free survival and overall survival. This single-center, retrospective study was performed to evaluate the role of the addition of R to chemotherapy $(\mathrm{CHT})$ in a real-world clinical setting. Outcomes were assessed in 85 patients with newly diagnosed DLBCL treated with CHT alone $(n=38)$ and R-CHT ( $n=47)$. Complete response (CR) rates were significantly higher after R-CHT than CHT (93\% vs. $73 \%$; $=0.02$ ). The relapse rate was significantly higher after CHT compared with R-CHT (38 \% versus $12 \%$; $=0.01$ ). Progression-free survival was significantly extended by the addition of $\mathrm{R}$ (median not reached versus 26.1 months; $\mathrm{p}=0.04$ ). These data bring further support for rituximab-based immunochemotherapy as a standard first-line therapy for patients with DLBCL.
\end{abstract}

Key words: Diffuse large B-cell lymphoma; Rituximab; Non-Hodgkin's lymphoma; Immunochemotherapy

\section{Introduction}

Diffuse large B-cell lymphoma (DLBCL) is the most common type of non-Hodgkin's lymphoma (NHL), accounting for $35 \%$ of newly diagnosed lymphomas (26). The majority of patients have systemic disease at the time of diagnosis and require chemotherapy. Since the introduction of anthracycline-based chemotherapy in the 1970s, DLBCL has been considered a potentially curable disease (9). The CHOP (cyclophosphamide, doxorubicin, vincristine, prednisone) regimen has been accepted as standard chemotherapy for patients with DLBCL for over 25 years, principally on the basis of the SWOG-8516 trial, which showed no benefit after intensification of therapy $(4,11)$.

The introduction of rituximab represents a major breakthrough in the treatment of patients with DLBCL. Rituximab (Rituxan ${ }^{\circledR}$, Genentech/Biogen Idec; MabThera ${ }^{\circledR}$, F. Hoffmann-La Roche AG) is a chimeric IgG1 monoclonal antibody that specifically binds to the CD20 B cell surface antigen. Its mechanisms of action are multiple and include complement-mediated lysis, antibody-dependent cytotoxicity, and induction of apoptosis $(1,2,12,13)$. The US Food and Drug Administration approved Rituximab in 1997 for patients with relapsed and refractory follicular lymphoma
(17). Early studies also indicated that rituximab monotherapy was active and well tolerated in patients with relapsed or refractory DLBCL (7).

A Phase II study of rituximab plus CHOP (R-CHOP) as first-line treatment of 33 patients with aggressive NHL yielded an overall response rate (ORR) of $94 \%$, with $61 \%$ complete responses (CR) (28). Long-term follow-up indicated that the remissions achieved were durable - at 5 years, progression-free survival (PFS) and overall survival (OS) rates were $87 \%$ and $80 \%$, respectively (27). In the pivotal, randomized Groupe d'Etude des Lymphomes de L'Adulte (GELA) LNH 98-5 trial conducted in elderly patients with previously untreated DLBCL, the addition of rituximab to CHOP resulted in significant improvements in the CR rate, which translated into significantly prolonged PFS, eventfree survival (EFS), and OS $(5,6,7)$. Importantly, the improvements in clinical outcome were achieved without any clinically significant increase in toxicity. The survival benefit for R-CHOP was maintained at the 5-year follow-up (10). These impressive results led to the establishment of $\mathrm{R}$ CHOP as a standard first-line treatment for patients with DLBCL.

Further studies have supported the clinical utility of combining rituximab with $\mathrm{CHOP}$ and $\mathrm{CHOP}$-like chemo- 
therapy in the treatment of newly diagnosed DLBCL, in younger as well as older patients $(14,15,18,23)$. ECOG 4494 was a Phase III study that in the first randomization evaluated the safety and efficacy of R-CHOP versus CHOP induction in elderly patients with previously untreated DLBCL and in a second randomization evaluated the efficacy of subsequent rituximab maintenance therapy in patients responding to induction (14-15). The 3-year failurefree survival (FFS) rate was significantly higher after R$\mathrm{CHOP} \pm$ maintenance versus $\mathrm{CHOP} \pm$ maintenance $(53 \%$ versus $46 \%$; $=0.04$ ), and after using weighted Cox's regression analysis to remove the confounding effect of maintenance therapy, both FFS and OS were significantly improved after R-CHOP induction compared with CHOP alone (3-year FFS: 52 \% versus $39 \%$; =0.003; 3-year OS: $67 \%$ versus $57 \%$; $=0.05)$. By contrast, preliminary data from a Phase II study of rituximab-containing chemotherapy induction followed by rituximab maintenance in a similar group of patients produced a 2-year PFS rate of $90 \%$, suggesting a potential role for rituximab maintenance after R-chemotherapy in this context (22).

Here we report on a retrospective analysis conducted to determine the clinical benefit conferred by the addition of rituximab to CHOP or other chemotherapy in patients newly diagnosed with DLBCL treated at the Charles University Hospital, Hradec Králové, Czech Republic, between January 2001 and November 2004.

\section{Patients and methods}

Study design. This was a retrospective study evaluating the role of adding rituximab to anthracycline-based chemotherapy in patients with newly diagnosed DLBCL. Patients were treated at the Hematology Department of Charles University Teaching Hospital in Hradec Králové between January 2001 and November 2004. The analysis was performed in March 2006, giving a minimum follow-up of 12 months from the data of termination of the last patient's therapy. This analysis compares two historically different treatment strategies (chemotherapy (CHT) alone versus rituximab plus CHT (R-CHT) used in the periods before and after September 2002, when rituximab was introduced at our institution for the treatment of newly diagnosed DLBCL.

Eligibility criteria. All patients with newly diagnosed, histologically verified DLBCL who were treated with CHOP or other anthracycline-based CHT with or without rituximab with curative intent were included in the analysis. Patients with primary central nervous system lymphoma were excluded from the analysis, owing to the lack of information on the efficacy of rituximab in this setting and the poor prognosis compared with other patients with DLCBL (24). Patients with localized disease treated with radiotherapy only were also excluded.

Treatment. All patients received anthracycline-based chemotherapy. Patients treated with CHOP-21 alone received a combination of cyclophosphamide, vincristine, doxorubicin, and prednisone at standard doses every 21 days. Other anthracycline-based chemotherapy regimens administered were $\mathrm{MegaCHOP} / \mathrm{ESAP} / \mathrm{BEAM}$ (intensified $\mathrm{CHOP} /$ etoposide, methylprednisolone, cytarabine/carmustine, cytarabine, etoposide, melphalan), hyperCVAD/HD-MTX + Ara-C (hyperfractionated cyclophosphamide, vincristine, doxorubicin, dexamethasone/high-dose methotrexate and cytarabine), and VACOP-B (vincristine, doxorubicin, cyclophosphamide, etoposide, prednisone, bleomycin). Patients treated with R-CHT received rituximab $375 \mathrm{mg} / \mathrm{m}^{2}$ intravenously on Day 1 of each cycle. Treatment was repeated every 21 days for a median of 6 (range 6-8) cycles.

Assessment of response. Efficacy variables including response rate and PFS were used to compare the CHT and R-CHT treatment schedules. Response criteria were used according to the report of the International Workshop to Standardize Response Criteria for Non-Hodgkin's Lymphoma (3). PFS was defined as the time from the date of diagnosis to documented disease progression and OS as the time from diagnosis until death from any cause.

Patients were followed up every 3 months after completion of therapy for the first 2 years and every 6 months thereafter. Routine examination of disease activity (computed tomography (CT) scan) was performed every 6 months in the first year and then once a year, or in the case of relapse/progression. Patients who relapsed/progressed were treated according to local clinical practice.

Toxicity. Toxicity of the treatments was assessed according to the standardized National Cancer Institute Common Toxicity Criteria, version 3.0.

Statistical analysis. Rituximab in combination with CHOP therapy was introduced into the first-line treatment of patients with DLBCL in the Czech Republic in September 2002. The analysis is based on follow-up data up to November 2005. Clinical and laboratory characteristics of patients treated with CHT only and R-CHT were compared.

Data were assessed according to the intention-to-treat principle; patients who received at least one cycle of therapy were included in the analysis. OS and PFS were estimated using the Kaplan-Meier method (15). Comparison of survival curves was performed using the log-rank test. Fisher's exact test was used for statistical analysis of variables between CHT and R-CHT groups. Data were analyzed using NCSS statistical software version 6.0.

\section{Results}

Patient characteristics. The analysis included 85 patients with newly diagnosed DLBCL (48 patients in the R-CHT group and 37 patients in the CHT group) with a median age of 59 years (range 20-81 years). Initial stage I/II/III/IV disease was found in 17/33/16/19 patients, respectively. Classification according to the International Prognostic Index (IPI) score showed that the majority of patients (65\%) had an IPI score of 2-5. Elevated lactate dehydrogenase 
(LDH) was present at the time of diagnosis in 64 patients (75\%), extranodal involvement in 53 patients (62\%), and bulky disease $>7 \mathrm{~cm}$ in 34 patients (40\%). The mediastinal variant of DLBCL was diagnosed in 14 cases ( $16 \%$ ). All patients were confirmed as having CD20-positive disease by immunohistochemistry. Treatment groups (CHT and RCHT) were well balanced with respect to disease stage, extranodal involvement, IPI score, and age (Tab. 1).

All patients received anthracycline-based chemotherapy. CHOP-21 with or without rituximab was given to 63 patients $(74 \%)$. Twenty patients $(24 \%)$ were treated with the MegaCHOP/ESAP/BEAM regimen with or without rituximab within a Phase II study of the Czech Lymphoma Study Group for patients under 65 years with intermediateand high-risk DLBCL (21). One patient received hyperCVAD/HD-MTX+Ara-C and one VACOP-B plus rituximab. Treatment groups were well balanced with respect to firstline treatment regimen and proportion of patients treated with the high-dose protocol (MegaCHOP/ESAP/BEAM with or without rituximab) (Tab. 2). Although rituximab was introduced for the treatment of patients with DLBCL in the Czech Republic in September 2002, 4 patients (14\%) received it before this date. In addition, 13 patients (23\%) were treated with chemotherapy only in the "early rituximab era."

Treatment response. At the time of reporting, 85 patients were evaluable for efficacy, 48 in the R-CHT group and 37 in the CHT group. Median follow-up for living patients was 31 months for the whole group (range 10-54 months), 21 months (range 10-33 months) in the R-CHT group, and 38.5 months (range 29-54 months) in the CHT arm.

Complete remissions were observed more frequently with R-CHT than with CHT (CR + CRu: $93 \%$ versus $73 \%$, $\mathrm{p}=0.02$ ) (Tab. 3). Multivariate analysis revealed administration of rituximab with CHT, low IPI (0/1), and stage I/II di-

Tab. 1: Patient characteristics in each treatment arm.

\begin{tabular}{|l|c|c|c|}
\hline Characteristic & $\begin{array}{c}\text { R-CHT } \\
(\mathrm{n}=48)\end{array}$ & $\begin{array}{c}\text { CHT } \\
(\mathrm{n}=37)\end{array}$ & p-value \\
\hline $\begin{array}{l}\text { Median age, years } \\
\text { (range) }\end{array}$ & $55(22-82)$ & $63(20-81)$ & 0.08 \\
\hline Male, \% & 62 & 59 & 0.82 \\
\hline Stage III/IV, \% & 48 & 32 & 0.19 \\
\hline $\begin{array}{l}\text { IPI score, \% } \\
\text { 0-1 } \\
\text { 2-5 }\end{array}$ & 33 & 40 & 0.51 \\
\hline Elevated LDH, \% & 83 & 65 & 0.08 \\
\hline $\begin{array}{l}\text { Primary mediastinal } \\
\text { DLBCL, \% }\end{array}$ & 21 & 11 & 0.25 \\
\hline $\begin{array}{l}\text { Bulky disease } \\
>7 \text { cm, \% }\end{array}$ & 50 & 27 & 0.05 \\
\hline $\begin{array}{l}\text { Extranodal } \\
\text { involvement, \% }\end{array}$ & 56 & 70 & 0.26 \\
\hline
\end{tabular}

CHT - anthracycline-based chemotherapy; DLBCL - diffuse large B-cell lymphoma: IPI - International Prognostic Index; LDH - lactate dehydrogenase; $\mathrm{R}$ - rituximab sease were all strong predictors of $\mathrm{CR}$ achievement after initial treatment (Tab. 4).

The rate of relapse or disease progression was significantly higher after CHT than R-CHT therapy (38\% versus $12 \% ; p=0.01$ ) (Tab. 3). There was also a significantly lower incidence of early relapses (i.e. within 12 months) in the RCHT arm compared with the CHT arm ( $8 \%$ versus $34 \%$; $\mathrm{p}=0.03$ ) (Tab. 3). Median time to disease progression or relapse was 10.5 months for all patients (range 6-28 months). The addition of rituximab to chemotherapy resulted in significantly better PFS - median PFS was significantly increased in the R-CHT group compared with the

Tab. 2: Type of first-line chemotherapy administered.

\begin{tabular}{|l|c|c|c|}
\hline & $\begin{array}{c}\text { R-CHT } \\
(\mathrm{n}=48)\end{array}$ & $\begin{array}{c}\text { CHT } \\
(\mathrm{n}=37)\end{array}$ & p-value \\
\hline CHOP-21 \pm R, \% & 69 & 81 & 0.22 \\
\hline $\begin{array}{l}\text { MegaCHOP/ESAP/ } \\
\text { BEAM } \pm \text { R, \% }\end{array}$ & 29 & 16 & 0.20 \\
\hline $\begin{array}{l}\text { Hyper-CVAD/HD } \\
\text { MTX-Ara-C, \% }\end{array}$ & 0 & 3 & NA \\
\hline VACOP-B + R, \% & 2 & 0 & NA \\
\hline
\end{tabular}

\section{Doses and Schedules:}

CHOP-21: Cyclophosphamide $750 \mathrm{mg} / \mathrm{m}^{2}$ IV D1, doxorubicin $50 \mathrm{mg} / \mathrm{m}^{2}$ IV D1, vincristine $1.4 \mathrm{mg} / \mathrm{m}^{2}$ IV D1 (maximum $2 \mathrm{mg}$ ), prednisone $100 \mathrm{mg}$ PO D1-5

MegaCHOP: Cyclophosphamide $3000 \mathrm{mg} / \mathrm{m}^{2}$ IV D1 (with mesna prophylaxis $3000 \mathrm{mg} / \mathrm{m}^{2}$ ), doxorubicin $75 \mathrm{mg} / \mathrm{m}^{2} \mathrm{IV}$ $\mathrm{D} 1$, vincristine $1.4 \mathrm{mg} / \mathrm{m}^{2}$ IV D1 (maximum dose $2 \mathrm{mg}$ ), prednisone $100 \mathrm{mg}$ D1-5 + filgrastim $5 \mu \mathrm{g} / \mathrm{kg} /$ day started D6 ESAP: Etoposide $60 \mathrm{mg} / \mathrm{m}^{2}$ IV D1-4, cisplatin $25 \mathrm{mg} / \mathrm{m}^{2}$ IVCI D1-4, cytarabine $2 \mathrm{~g} / \mathrm{m}^{2}$ IV D5, methylprednisolone 500 mg IV D1-4

BEAM: Carmustine $300 \mathrm{mg} / \mathrm{m}^{2}$ IV D-7, etoposide 300 $\mathrm{mg} / \mathrm{m}^{2}$ IV D-7 to -4 , cytarabine $400 \mathrm{mg} / \mathrm{m}^{2}$ IV D-7 to -4 , melphalan $140 \mathrm{mg} / \mathrm{m}^{2}$ IV D-3

Hyper-CVAD: Cyclophosphamide $300 \mathrm{mg} / \mathrm{m}^{2}$ IV q 12 h D1-3, doxorubicin $16.6 \mathrm{mg} / \mathrm{m}^{2}$ IVCI over $72 \mathrm{~h} \mathrm{D} \mathrm{4-5,}$ vincristine $1.4 \mathrm{mg} / \mathrm{m}^{2}$ IV D5+12 (maximum $2 \mathrm{mg}$ ), dexamethasone $40 \mathrm{mg}$ IV or PO D1-4 and D11-14 + G-CSF 5 $\mu \mathrm{g} / \mathrm{kg} /$ day started D7

MTX-Ara-C: Methotrexate $200 \mathrm{mg} / \mathrm{m}^{2}$ IV over $2 \mathrm{~h} \mathrm{D} 1$, methotrexate $800 \mathrm{mg} / \mathrm{m}^{2}$ IVCI over $22 \mathrm{~h} \mathrm{D1}$, cytarabine 3 $\mathrm{g} / \mathrm{m}^{2} \mathrm{IV}$ over $2 \mathrm{~h} \mathrm{q} 12 \mathrm{~h}$ x 4 D2-3 + G-CSF $5 \mu \mathrm{g} / \mathrm{kg} /$ day started D4

VACOP B: Doxorubicin $50 \mathrm{mg} / \mathrm{m}^{2}$ IV D1 wk 1, 3, 5, 7, 9, 11, cyclophosphamide $350 \mathrm{mg} / \mathrm{m}^{2}$ IV D1 wk 1, 5, 9, vincristine $1.2 \mathrm{mg} / \mathrm{m}^{2} \mathrm{IV}$ (maximum dose $2 \mathrm{mg}$ ) IV D1 wk 2, 4, 6, 8, 10,12 , bleomycin $10 \mathrm{mg} / \mathrm{m}^{2}$ IV D1 wk 2, 4, 6, 8, 10, 12, etoposide $50 \mathrm{mg} / \mathrm{m}^{2}$ IV D1 and $100 \mathrm{mg} / \mathrm{m}^{2} \mathrm{D} 2-3 \mathrm{wk} 3,7,11$

CHT - anthracycline-based chemotherapy; D - day; IV intravenously; IVCI - intravenously as continuous infusion; MTX - methotrexate; NA - not applicable; PO - per os; q every; $\mathrm{R}$ - rituximab 
Tab. 3: Clinical outcomes according to treatment arm.

\begin{tabular}{|l|c|c|c|}
\hline \multirow{2}{*}{ Outcome } & \multicolumn{3}{|c|}{ Rate (\%) } \\
\cline { 2 - 4 } & $\begin{array}{c}\text { R-CHT } \\
(\mathrm{n}=48)\end{array}$ & $\begin{array}{c}\text { CHT } \\
(\mathrm{n}=37)\end{array}$ & p-value \\
\hline Cru + CR & 93 & 73 & 0.02 \\
\hline Any events & 23 & 43 & 0.05 \\
\hline Relapse/progression & 12 & 38 & 0.01 \\
\hline Relapse/progression < 12 months & 8 & 34 & 0.02 \\
\hline Death & 15 & 30 & 0.11 \\
\hline 2-year PFS & 82 & 55 & 0.04 \\
\hline
\end{tabular}

CHT - anthracycline-based chemotherapy; CR - complete response; $\mathrm{CRu}$ - complete response, unconfirmed; PFS progression-free survival; $\mathrm{R}$ - rituximab

Tab. 4: $\mathrm{CR} / \mathrm{CRu}$ after first-line treatment.

\begin{tabular}{|ll|c|c|}
\hline Characteristic & & CR/CRu rate (\%) & p-value \\
\hline Stage I/II disease & Yes & 93 & \\
& No & 73 & 0.02 \\
\hline Elevated serum LDH & Yes & 86 & \\
& No & 84 & 1.0 \\
\hline IPI 0/1 & Yes & 97 & \\
& No & 78 & 0.02 \\
\hline Bulky disease $>7 \mathrm{~cm}$ & Yes & 83 & \\
& No & 86 & 0.75 \\
\hline Primary mediastinal & Yes & 90 & \\
DLBCL & No & 84 & 0.70 \\
\hline Extranodal involvement & Yes & 80 & \\
& No & 93 & 0.12 \\
\hline Rituximab in initial & Yes & 93 & \\
therapy & No & 73 & 0.02 \\
\hline Use of radiotherapy & Yes & 81 & \\
& No & 87 & 0.74 \\
\hline First-line HDT & Yes & 85 & \\
with ASCT & No & 84 & 1.0 \\
\hline
\end{tabular}

ASCT - autologous stem cell transplantation; CR - complete remission; $\mathrm{CRu}$ - complete remission unconfirmed; DLBCL - diffuse large B-cell lymphoma; HDT - high-dose therapy; IPI - International Prognostic Index; LDH - lactate dehydrogenase.

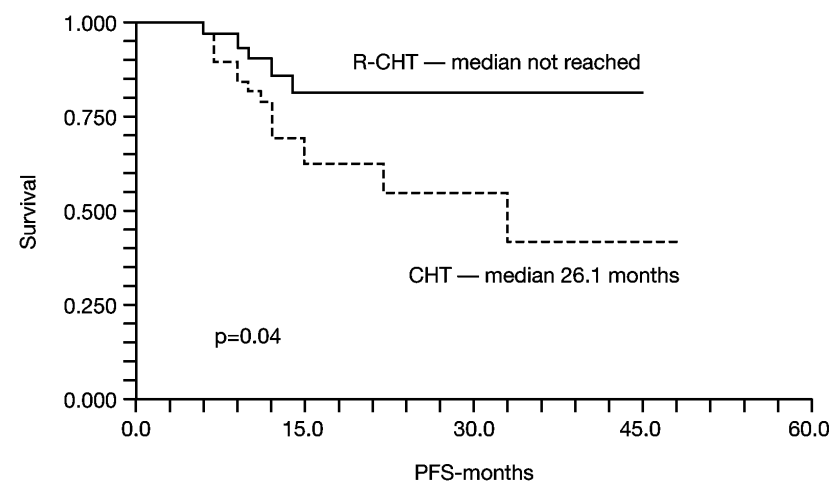

Fig. 1:. Kaplan-Meier curves of progression-free survival according to treatment (R-CHT or CHT).
CHT group (median not reached versus 26.1 months; $\mathrm{p}=0.04$ ) (Fig. 1). Despite the trend to prolonged overall survival in R-CHT arm, the difference was not statistically significant at the time of assessment. Nineteen of twenty patients received further treatment at relapse or disease progression. Nine received palliative therapy, 6 patients were treated with salvage chemotherapy (R-ICE or RESAP) and 4 received salvage chemotherapy (R-ICE) followed by high-dose chemotherapy and autologous stem cell transplantation. Seven patients responded to second-line therapy, yielding an ORR of $37 \%$ (6 CRs and 1 PR). The actuarial 2-year PFS and OS rates for the entire group were $65 \%$ and $84 \%$, respectively.

Toxicity. The predominant toxicity was hematologic (Tab. 5). Grade 3 and 4 thrombocytopenia and neutropenia occurred in $34 \%$ and $38 \%$ of patients, respectively. The majority of observed toxicities were seen in patients receiving the MegaCHOP/ESAP regimen with or without rituximab with autologous stem cell transplantation. Neutropenic fever occurred in $25 \%$ and $19 \%$ of patients in the R-CHT and CHT arms, respectively. All of these patients were treated with the intensive protocol described above. There were 10 grade $3 / 4$ infections -5 in each arm - comprising 7 cases of pneumonias (two of them of fungal origin), 2 cases of severe neutropenic sepsis, and 1 central venous catheter sepsis. Other common toxicities included nausea and/or vomiting (grade $3 / 4$ in $12 \%$ of patients). Venous thromboembolism occurred in 4 patients, and 1 patient developed dilation cardiomyopathy, probably related to anthracycline therapy. There were no statistically significant differences between the R-CHT and CHT groups in terms of the main toxicities observed (Tab. 5).

Tab. 5: Toxicities by treatment arm.

\begin{tabular}{|c|c|c|c|}
\hline Toxicity & $\begin{array}{l}\text { R-CHT } \\
(n=48)\end{array}$ & $\begin{array}{c}\text { CHT } \\
(n=37)\end{array}$ & p-value \\
\hline & \multicolumn{3}{|c|}{ Rate (\%) } \\
\hline $\begin{array}{l}\text { Thrombocytopenia } \\
3 / 4 \text { grade }\end{array}$ & 39 & 30 & 0.49 \\
\hline $\begin{array}{l}\text { Neutropenia grade } \\
3 / 4\end{array}$ & 37 & 40 & 0.82 \\
\hline Neutropenic fever & 25 & 19 & 0.60 \\
\hline \multirow[t]{2}{*}{$\begin{array}{l}\text { Nausea/vomiting, } \\
\text { grade } 3 / 4\end{array}$} & 13 & 12 & 1.0 \\
\hline & \multicolumn{3}{|c|}{ No. of events } \\
\hline \multicolumn{4}{|l|}{ Infection } \\
\hline Pneumonia & 4 & 3 & \\
\hline Bacteremia & 1 & 2 & \\
\hline \multicolumn{4}{|l|}{ Other } \\
\hline $\begin{array}{l}\text { Deep venous } \\
\text { thrombosis }\end{array}$ & 2 & 2 & \\
\hline Myocardial infarction & 0 & 1 & \\
\hline $\begin{array}{l}\text { Dilatation } \\
\text { cardiomyopathy }\end{array}$ & 1 & 0 & \\
\hline
\end{tabular}

CHT - anthracycline-based chemotherapy; R - rituximab 


\section{Discussion}

The treatment outcome for patients with DLBCL has dramatically improved since the addition of the anti-CD20 monoclonal antibody rituximab to chemotherapy protocols. The major benefit of rituximab lies in its ability to improve efficacy with no significant additional toxicity. Many studies have been conducted to assess the potential benefits of rituximab-based chemoimmunotherapy. In the pivotal GELA LNH 98-5 trial in elderly patients with previously untreated DLBCL, the addition of rituximab to CHOP conferred a significant improvement in complete response rate and EFS as well as in overall survival $(5,6,7)$. The improvements in clinical outcomes, including overall survival benefit, were maintained at the 5-year follow-up (10).

Results of the MabThera International Trial (MInT) support the clinical utility of the addition of rituximab to CHOP and CHOP-like chemotherapy in newly diagnosed aggressive NHL in low-risk patients aged 60 and under 60 (18). The British Columbia population-based retrospective analysis has shown that patients treated in the "rituximab era" had an $18 \%$ improvement in 2-year PFS and $25 \%$ improvement in 2-year OS compared with those in the "pre-rituximab era." The period of treatment was an independent strong predictor of outcome, with respect to better PFS and OS, for patients in the "rituximab era" (23). Although the results of the ECOG 4494 study of R-CHOP versus CHOP in elderly patients with DLBCL were less clear-cut, this is likely to be a result of the confounding effects of maintenance therapy and possibly the different administration schedules used ( 8 cycles of rituximab and CHOP in the GELA study compared with 4-5 cycles of rituximab and 6-8 cycles of CHOP in ECOG 4494) (14-15).

The benefit of adding rituximab to chemotherapy in younger intermediate- and high-risk (age-adjusted IPI 2-3) patients under 60 years of age remains unproven. The optimal intensity of chemotherapy also remains unclear. Pfreundschuh and colleagues have conducted a study evaluating dose and/or time intensification of CHOP by shortening treatment intervals from 3 to 2 weeks (CHOP-14) and/or adding etoposide to CHOP (CHOEP) in patients with aggressive lymphoma. Time intensification significantly improved the time to treatment failure in patients 60 years of age and older (19). The RICOVER-60 trial has investigated the addition of 8 cycles of rituximab to 6 or 8 cycles of CHOP-14 in comparison with 6 or 8 cycles of CHOP-14 alone (20). Preliminary results show that the addition of 8 doses of rituximab to 6 cycles of CHOP-14 is associated with an optimal outcome in patients newly diagnosed with DLBCL over 60 years old. No benefit of 8 cycles of CHOP-14 chemotherapy has been shown in comparison with 6 cycles of CHOP-14 (20).

Our retrospective analysis was performed to evaluate the clinical benefit of the addition of rituximab to CHOP or other anthracycline-based chemotherapy in the first-line treatment of patients with DLBCL. Although this study is not a concurrent comparison or randomized trial, our results support the essential role of rituximab-based chemoimmunotherapy in improving clinical outcomes in patients with DLBCL. The addition of rituximab to chemotherapy yielded an improved $\mathrm{CR}$ rate compared with chemotherapy alone. The increased response rate with R-CHT translated into a PFS benefit. R-CHT was associated with significantly prolonged PFS compared with CHT alone. Although longer follow-up is required to determine any overall survival benefit, these data lend further support to the clinical utility of the addition of rituximab to chemotherapy for the first-line management of DLBCL in routine clinical practice.

Results of ongoing randomized trials are expected to answer some key questions, including the most appropriate chemotherapy regimen to be combined with rituximab, the optimal timing, the level of dose to be administered, and the duration of therapy for individual patients (25). Many questions are still to be answered in this field, but the combination of rituximab and chemotherapy is generally accepted as the current standard for all patients with newly diagnosed DLBCL. The addition of rituximab to chemotherapy presents a milestone in the treatment of patients with DLBCL in the last 20 years.

\section{Acknowledgements}

This work was supported by research project MZO 00179906 from Ministry of Health, Czech Republic, and by grant NR 8231-3/2004 from Internal Grant Agency, Ministry of Health, Czech Republic.

\section{References}

1. Anderson DR, Grillo-Lopez A, Varns C, Chambers KS, Hanna N. Targeted anticancer therapy using rituximab, a chimeric anti-CD20 antibody (IDEC-C2B8) in the treatment of non-Hodgkin's B-cell lymphoma. Biochem Soc Trans 1997;25: 705-8.

2. Cartron G, Watier H, Golay J, Solal-Celigny P. From the bench to the bedside: ways to improve rituximab efficacy. Blood 2004:104:2635-42.

3. Cheson BD, Horning SJ, Coiffier B, Shipp MA, Fisher RI, Connors JM, Lister TA, Vose J, Grillo-Lopez A, Hagenbeek A, Cabanillas F, Klippstein D, Hiddemann W, Castelino R, Harris NL, Armitage JO, Carter W, Hoppe R, Canellos GP. Report of an international workshop to standardize response criteria for nonHodgkin's lymphomas. J Clin Oncol 1999;17:1244. Erratum in: J Clin Oncol 2000; $18: 2351$.

4. Coiffier B. Increasing chemotherapy intensity in aggressive lymphomas: a renewal? J Clin Oncol 2003;21:2457-9.

5. Coiffier B. Effective immunochemotherapy for aggressive non-Hodgkin's lymphoma. Semin Oncol 2004;31(1 Suppl. 2):7-11

6. Coiffier B. Treatment of diffuse large B-cell lymphoma. Curr Hematol Rep 2005;4:7-14

7. Coiffier B, Haioun C, Ketterer N, Engert A, Tilly H, Ma D, Johnson P, Lister A Feuring-Buske M, Radford JA, Capdeville R, Diehl V, Reyes F. Rituximab (antiCD20 monoclonal antibody) for the treatment of patients with relapsing or refractory aggressive lymphoma: a multicenter phase II study. Blood 1998;92: 1927-32.

8. Coiffier B, Lepage E, Briere J, Herbrecht R, Tilly H, Bouabdallah R, Morel P, Van den Neste E, Salles G, Gaulard P, Reyes F, Lederlin P, Gisselbrecht C. CHOP chemotherapy plus rituximab compared with CHOP alone in elderly patients with diffuse large-B-cell lymphoma. N Engl J Med 2002;346:235-42.

9. Devita VT Jr, Canellos GP, Chabner B, Schein P, Hubbard SP, Young RC. Advanced diffuse histiocytic lymphoma, a potentially curable disease. Lancet $1975 ; 1: 248-50$ 
10. Feugier P, Van Hoof A, Sebban C, Solal-Celigny P, Bouabdallah R, Ferme C, Christian B, Lepage E, Tilly H, Morschhauser F, Gaulard P, Salles G, Bosly A, Gisselbrecht C, Reyes F, Coiffier B. Long-term results of the R-CHOP study in the treatment of elderly patients with diffuse large B-cell lymphoma: a study by the Groupe d'Etude des Lymphomes de l'Adulte. J Clin Oncol 2005;23:4117-26.

11. Fisher RI, Gaynor ER, Dahlberg S, Oken MM, Grogan TM, Mize EM, Glick JH, Coltman CA JR, Miller TP. A phase III comparison of CHOP vs. m-BACOD vs. ProMACE-CytaBOM vs. MACOP-B in patients with intermediate- or high-grade non-Hodgkin's lymphoma: results of SWOG-8516 (Intergroup 0067), the National High-Priority Lymphoma Study. Ann Oncol 1994;5(Suppl. 2):91-95.

12. Grillo-Lopez AJ. Rituximab (Rituxan/MabThera): the first decade (1993-2003). Expert Rev Anticancer Ther 2003;3:767-79.

13. Grillo-Lopez AJ. Rituximab: an insider's historical perspective. Semin Oncol 2000;27(6 Suppl. 12):9-16.

14. Habermann TM, Weller EA, Morrison VA, Cassileth PA, Cohn JB, Dakhil SR, Gascoyne RD, Woda B, Fisher RI, Peterson BA, Horning SJ. Phase III trial of rituximab-CHOP (R-CHOP) vs. CHOP with second randomization to maintenance rituximab (MR) or observation in patients 60 years of age and older with diffuse large B-cell lymphoma (DLBCL). Blood 2003;102(Suppl.):6a (abstract 8).

15. Habermann TM, Weller EA, Morrison WA, Gascoyne RD, Cassileth PA, Cohn JB, Dakhil SH, Woda B, Fisher RI, Peterson BA, Horning SJ. Rituximab-CHOP versus $\mathrm{CHOP}$ alone or with maintenance rituximab in older patients with diffuse large B-cell lymphoma. J Clin Oncol 2006;24:3121-7.

16. Kaplan EL, Meier P. Nonparametric estimation from incomplete observations. J Am Stat Assoc 1958;53:457-81.

17. McLaughlin P, Grillo-Lopez AJ, Link BK, Levy R, Czuczman MS, Williams ME, Heyman MR, Bence-Bruckler I, White CA, Cabanillas F, Jain V, Ho AD, Liste J, Wey K, Shen D, Dallaire BK. Rituximab chimeric anti-CD20 monoclonal antibody therapy for relapsed indolent lymphoma: half of patients respond to a fourdose treatment program. J Clin Oncol 1998;16:2825-33.

18. Pfreundschuh M, Trumper L, Osterborg A, Pettengell R, Trneny M, Imrie K, Ma D, Gill D, Walewski J, Zinzani PL, Stahel R, Kvaloy S, Shpilberg O, Jaeger U, Hansen M, Lehtinen T, Lopez-Guillermo A, Corrado C, Scheliga A, Milpied N, Mendila M, Rashford M, Kuhnt E, Loeffler M;Mabthera International Tria Group. CHOP-like chemotherapy plus rituximab versus CHOP-like chemotherapy alone in young patients with good-prognosis diffuse large-B-cell lymphoma: a randomised controlled trial by the MabThera International Trial (MInT) Group. Lancet Oncol 2006; 7:379-91.

19. Pfreundschuh M, Trumper L, Kloess M, Schmits R, Feller AC, Rube C, Rudolph C, Reiser M, Hossfeld DK, Eimermacher H, Hasenclever D, Schmitz N, Loeffler M: German High-Grade Non-Hodgkin's Lymphoma Study Group. Two-weekly or 3-weekly CHOP chemotherapy with or without etoposide for the treatment of elderly patients with aggressive lymphomas: results of the NHL-B2 trial of the DSHNHL. Blood 2004;104:634-41.

20. Pfreundschuh M, Kloess M, Schmits R, Zeynalova S, Lengfelder E, Franke A, Steinhauer H, Reiser M, Clemens M, Nickenig C, De Wit M, Hoffmann M, Mertelsmann R, Metzner B, Ho A, Truemper L, Eimermacher H, Mergenthaler H, Liersch R, Duehrsen U, Balleisen L, Hartmann F, Poeschel V, Schmitz N, Loeffler M. Six, not eight cycles of bi-weekly CHOP with rituximab (R CHOP14 ) is the preferred treatment for elderly patients with diffuse large B-cell lymphoma (DLBCL): Results of the RICOVER-60 trial of the German High-Grade Non-Hodgkin's Lymphoma Study Group (DSHNHL). Blood 2005;106(Suppl.): 9a (abstract 13)

21. Pytlík R, Trněný M, Belada D, Kubáčková K, Vášová I, Jankovská M, Klener $P$ for the Czech Lymphoma Study Group. Treatment of 101 high-risk aggressive Bcell lymphoma patients with MegaCHOP-BEAM regimen \pm rituximab: the evolution of the concept. Ann Oncol 2005;165(Suppl. 5):v175-v176 (abstract 473).

22. Raefsky EL, Greco FA, Spigel DR, Doss HH, Farley C, Saez R, Kommor M, Hainsworth JD. Brief duration rituximab(R)/chemotherapy (CNOP or CVP) followed by maintenance rituximab in elderly/poor performance status patients (pts) with diffuse large B-cell lymphoma (DLBCL): a phase II trial of the Minnie Pearl Cancer Research Network. J Clin Oncol 2006;24(Suppl. 128S) (abstract 7577).

23. Sehn LH, Donaldson J, Chhanabhai M, Fitzgerald C, Gill K, Klasa R, MacPherson N, O'Reilly S, Spinelli JJ, Sutherland J, Wilson KS, Gascoyne RD, Connors JM. Introduction of combined CHOP plus rituximab therapy dramatically improved outcome of diffuse large B-cell lymphoma in British Columbia. J Clin Oncol 2005;23:5027-33.

24. Shah GD, Deangelis LM. Treatment of primary central nervous system lymphoma. Hematol Oncol Clin North Am 2005;19:611-27.

25. Schmits R, Schmitz N, Pfreundschuh M;German High-Grade Non-Hodgkin's Lymphoma Study Group. The best treatment for diffuse large B-cell lymphoma: a German perspective. Oncology (Williston Park) 2005;19(4 Suppl. 1);16-22.

26. Stein H. The new WHO classification of malignant lymphoma. After "REAL" a further step on the road to a worldwide consensus. Pathologe 2000;21:101-5.

27. Vose JM, Link BK, Grossbard ML, Czuczman M, Grillo-Lopez A, Fisher RI Long-term update of a phase II study of rituximab in combination with CHOP chemotherapy in patients with previously untreated, aggressive non-Hodgkin's lymphoma. Leuk Lymphoma 2005;46:1569-73.

28. Vose JM, Link BK, Grossbard ML, Czuczman M, Grillo-Lopez A, Gilman P, Lowe A, Kunkel LA, Fisher RI. Phase II study of rituximab in combination with CHOP chemotherapy in patients with previously untreated, aggressive nonHodgkin's lymphoma. J Clin Oncol 2001;19:389-97.

Submitted March 2007. Accepted May 2007.

\section{Corresponding author:}

David Belada, M.D., Charles University in Prague, Faculty of Medicine and University Hospital in Hradec Králové, Czech Republic; 2nd Department of Medicine, Division of Clinical Hematology, e-mail: david.belada@seznam.cz 